\title{
Determinants of Maternal Mortality: In a Tertiary Care Hospital of Central India
}

\author{
Priyanka Tiwari ${ }^{1}$, Jagrati Kiran Nagar ${ }^{2}$, Ravikant Arjariya ${ }^{3}$, Shikha Pandey ${ }^{4}$ \\ ${ }^{1}$ Assistant Professor, ${ }^{2}$ Associate Professor, ${ }^{4}$ Professor, Department of Obstetrics \& Gynaecology, \\ BMC, Sagar, M.P., ${ }^{3}$ Associate Professor, Department of Physiology, BMC, Sagar, M.P.
}

\begin{abstract}
Introduction: Maternal mortality is unacceptably high. About 295000 women died during and following pregnancy and childbirth in 2017. The vast majority of these deaths (94\%) occurred in low-resource settings, and most could have been prevented. Women face high risk of maternal deaths in south Asia and sub Saharan Africa· ${ }^{(1)}$
\end{abstract}

Aims and Objective: To identify causes of maternal deaths in a tertiary care hospital.

Materials and Method: This is a retrospective study conducted in a tertiary level hospital of Bundelkhand Medical College Sagar M.P. in central India. A retrospective case record examined related to maternal mortality in hospital setting. Ethical approval was obtained from Institutional ethical committee.

Data was collected in predesigned proforma.

Data were analyzed for age, gravidity, trimester of pregnancy, duration of deaths and causes of death.

Results: During $1^{\text {st }}$ January 2018 to 31 December 2019, 44 maternal deaths amongst 11944 live births occurred in obstetrics department of Bundelkhand Medical College Sagar M.P. India.

Most no. of deaths occurs in age between 21-30 years (86.4\%) followed by 31-40 years (6.8\%).

The maternal mortality ratio (MMR) stood at 368 per lac live births. $31 \%$ were primigravida.

The leading causes of death were Pre-eclampsia \& Eclampsia (34\%), Severe Anaemia (20\%) and Hepatic encephalopathy $(13 \%)$.

Conclusions: Based on the results we found that hypertensive disorder (Pre-eclampsia \& Eclampsia) is an important cause of maternal mortality followed by Severe Anaemia, Hepatic encephalopathy, Septic abortion and postpartum haemorrhage.

Maternal mortality is a reflection of the standards of obstetric service and quality of healthcare. The audit of such mortality would help in identifying the problems and prevent recurrence by taking appropriate measures.

Hence the present study was conducted at tertiary care hospital to review the maternal deaths and causes of maternal mortality.

Keywords: Maternal Mortality, Eclampsia, Maternal Mortality Ratio, Post Partum Hemorrhage.

\section{Corresponding Author:}

Dr. Ravikant Arjariya

Associate Professor, Department of Physiology, BMC,

Sagar, M.P., H.No. 2, Type III, Block 'A’ Residential

complex, BMC Sagar,M.P. 470001

e-mail: arjariyaravikant@gmail.com

Mob.: 7898573595

\section{Introduction}

Maternal death or maternal mortality is defined by the World Health Organization (WHO) as "The death of a woman while pregnant or within 42 days of termination of pregnancy, irrespective of the duration and site of the 
pregnancy, from any cause related to or aggravated by the pregnancy or its management but not from accidental or incidental cause $\mathrm{e}^{(2,3)}$.

Adding to the WHO definition, the CDC extends the period of consideration to include up to 1 year within the end of a pregnancy regardless of the outcome ${ }^{(4)}$.

There are two performance indicators that are sometimes used interchangeably: maternal mortality ratio and maternal mortality rate, which confusingly both are, abbreviated "MMR" (5).

By 2017, the world maternal mortality rate had declined $44 \%$ since 1990 , but still every day 830 women die from pregnancy or childbirth related causes. According to the United Nations Population Fund (UNFPA) 2017 report, this is equivalent to "about one woman every two minutes and most of these deaths and injuries are entirely preventable.

Although attempts have been made in reducing maternal mortality, there is much room for improvement. Over $85 \%$ of maternal deaths are from impoverished communities in Africa and Asia. The effect of a mother's death results in vulnerable families. Their infants, if they survive childbirth, are more likely to die before reaching their second birthday ${ }^{(6)}$.

In the context of the Sustainable Development Goals (SDG), countries have united behind a new target to accelerate the decline of maternal mortality by 2030 . SDG 3 includes an ambitious target: "reducing the global MMR to less than 70 per 100000 births, with no country having a maternal mortality rate of more than twice the global average".

According to the Sample registration system, Registrar General of India (November 2019), Maternal mortality ratio of India is 122 per 1 lakh live births and MMR of Madhya Pradesh is 188 per1 lakhlive births. ${ }^{(7)}$

In present study MMR was 368 per 100000 live births. High MMR reveled in present study may be due to the fact that in our study place was a tertiary care centre and referral centre so un-booked obstetric cases were referred here in emergency for management.

\section{Materials and Method}

Ethics approval to conduct the study was obtained from the Institutional Ethics Committee.
A retrospective study was conducted in Bundelkhand Medical College and associated hospitals Sagar M.P. which is a tertiary care hospital in the Bundelkhand region of central India in which a review of all maternal deaths which occurred over a two-year period (January 2018 to December 2019) was done.

The hospital maternal death register was used to identify and collect a list of maternal deaths that occurred during the study period. Medical records of maternal deaths were reviewed. Information on all the cases was extracted from the patient's case notes and maternal mortality records. The total deliveries and live births for each year were obtained from the delivery registers.

The confidentiality of the patient's personal information was protected.

The data collected included maternal age, gestation age, referring facility, date of admission, date of death and cause of death. Data was captured and analyzed using Microsoft Excel and Descriptive statistics was used to analyses data. Categorical variables are displayed as percentages.

\section{Observations and Results:}

During $1^{\text {st }}$ January 2018 to 31 December 2019, 44 maternal deaths amongst 11944 deliveries occurred in obstetrics department of Bundelkhand Medical College Sagar M.P. India.

The maternal mortality ratio (MMR) stood at 368 per lac live births.

Table No. 1: Age distribution of maternal deaths.

\begin{tabular}{|c|c|c|c|}
\hline S.No. & Age (in years) & No. of Deaths & \% of Deaths \\
\hline 1 & $<20$ & 2 & $4.5 \%$ \\
\hline 2 & $21-30$ & 38 & $86.4 \%$ \\
\hline 3 & $31-40$ & 3 & $6.8 \%$ \\
\hline 4 & $>40$ & 1 & $2.3 \%$ \\
\hline \multicolumn{2}{|r|}{} & Total $=44$ & $100 \%$ \\
\hline
\end{tabular}

Most no. of deaths occurs in age between 21-30 years $(86.4 \%)$ followed by $31-40$ years $(6.8 \%)$. 
Table No. 2: Case characteristics of reviewed maternal death

\begin{tabular}{|c|l|c|c|}
\hline S.No. & Reason for admission & $\begin{array}{c}\text { Number } \\
\text { of Deaths }\end{array}$ & $\begin{array}{c}\text { \% of } \\
\text { Deaths }\end{array}$ \\
\hline 1 & Routine labour & 1 & $2.27 \%$ \\
\hline 2 & $\begin{array}{l}\text { Obstetrics complication } \\
\text { and also in labour }\end{array}$ & 5 & $11.36 \%$ \\
\hline 3 & $\begin{array}{l}\text { Obstetrics complication } \\
\text { not in labour }\end{array}$ & 26 & $59.09 \%$ \\
\hline 4 & Complication post partum & 12 & $27.28 \%$ \\
\hline & & Total $=44$ & $100 \%$ \\
\hline
\end{tabular}

Most no. of deaths occurs due to obstetrics complication not in labour $26(59.09 \%)$ followed by deaths occurs due to complication post partum 12 (27.28\%).

Table No. 3: Referral from another health facility

\begin{tabular}{|c|l|c|c|}
\hline S.No. & $\begin{array}{l}\text { Referral from another } \\
\text { health facility (Yes/No) }\end{array}$ & $\begin{array}{c}\text { No. of } \\
\text { Deaths }\end{array}$ & $\begin{array}{c}\text { \% of } \\
\text { Deaths }\end{array}$ \\
\hline 1 & Yes & 24 & $55 \%$ \\
\hline 2 & No & 20 & $45 \%$ \\
\hline
\end{tabular}

Higher rate of death found in patients referred from other health facility $(55 \%)$.

Table No. 4: Pregnancy stage at the time of death

\begin{tabular}{|c|l|c|c|}
\hline S.No. & Pregnancy stage & $\begin{array}{c}\text { No. of } \\
\text { Deaths }\end{array}$ & $\begin{array}{c}\text { \% of } \\
\text { Deaths }\end{array}$ \\
\hline 1 & During pregnancy & 20 & $45.5 \%$ \\
\hline 2 & During labour & 1 & $2.3 \%$ \\
\hline 3 & Postnatal-Vaginal delivery & 14 & $31.8 \%$ \\
\hline 4 & Postnatal- LSCS & 6 & $13.6 \%$ \\
\hline 5 & Post abortion & 3 & $6.8 \%$ \\
\hline
\end{tabular}

Most of women died during pregnancy (44.5\%), followed by death during postnatal -vaginal delivery $(31.8 \%)$.

Table No. 5: Time from admission to death

\begin{tabular}{|c|l|c|c|}
\hline S.No. & $\begin{array}{l}\text { Time from admission to } \\
\text { death }\end{array}$ & $\begin{array}{c}\text { No. of } \\
\text { Deaths }\end{array}$ & $\begin{array}{c}\text { \% of } \\
\text { Deaths }\end{array}$ \\
\hline 1 & $0-6 \mathrm{hrs}$ & 15 & $34 \%$ \\
\hline 2 & $7-12 \mathrm{hrs}$ & 11 & $25 \%$ \\
\hline 3 & $13-24 \mathrm{hrs}$ & 5 & $11.4 \%$ \\
\hline 4 & $25-48 \mathrm{hrs}$ & 10 & $22.8 \%$ \\
\hline 5 & $>48 \mathrm{hrs}$ & 3 & $6.8 \%$ \\
\hline & & Total $=44$ & $100 \%$ \\
\hline
\end{tabular}

Most of women died during 0-6 hrs of delivery (34\%), followed by time between 7-12 hours of delivery $(25 \%)$.

Table No. 6: Causes of deaths

\begin{tabular}{|c|l|c|c|}
\hline S.No. & Cause of Deaths & $\begin{array}{c}\text { No. of } \\
\text { Deaths }\end{array}$ & $\begin{array}{c}\text { \% of } \\
\text { Deaths }\end{array}$ \\
\hline 1 & Pre-eclampsia \& Eclampsia & 15 & $34 \%$ \\
\hline 2 & Severe Anaemia & 9 & $20 \%$ \\
\hline 3 & Hepatic encephalopathy & 6 & $13 \%$ \\
\hline 4 & Septic abortion & 5 & $11 \%$ \\
\hline 5 & PPH & 4 & $9 \%$ \\
\hline 6 & Pulmonary oedema & 2 & $4.5 \%$ \\
\hline 7 & Ruptured uterus & 1 & $2.3 \%$ \\
\hline 8 & Septicemia & 1 & $2.3 \%$ \\
\hline 9 & Ante partum hemorrhage & 1 & $2.3 \%$ \\
\hline
\end{tabular}

The leading causes of death in descending order are Pre-eclampsia \& Eclampsia (34\%), Severe Anaemia (20\%), Hepatic encephalopathy (13\%), Septic abortion (11\%), \& PPH ((9\%).

\section{DISCUSSION}

In the present study, there were 44 maternal deaths amongst 11944 deliveries occurred in obstetrics department of Bundelkhand Medical College Sagar M.P. India. The Maternal Mortality Ratio (MMR) stood at 368 per lac live births.

High MMR reveled in present study may be due to the fact that in our study place was a tertiary care centre and referral centre so un-booked obstetric cases were referred here in emergency for management, delayed referrals and moribund patients at the time of admission inflated the maternal deaths.

Our observations correlate with other studies in where the maternal mortality ratio ranged between 113

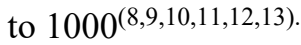

In the present study, $86.4 \%$ deaths were in age group 21-30 and $4.5 \%$ deaths were due to teenage pregnancies, $6.8 \%$ deaths in mothers above 30 years.

These findings correlate with other studies; $\mathrm{Dr}$ Sandhya Gupta et al reported $74.3 \%$ maternal death occurred in the age group of 21-30 years, ${ }^{(8)}$

K. V. S. M. Sandhya Devi et al. reported maternal death $48.45 \%$ were in the age group of $21-25$ years. 
Teenage pregnancies constituted about 17.53\%. Maternal deaths in age group above 25 years were $34.02 \%$. (9)

Vidyadhar et. al. reported $55.2 \%$ deaths in age group $19-24,15.79 \%$ deaths in $<19$ years ${ }^{(14)}$

Saini and Gupta,et.al. reported $81.69 \%$ deaths in age group 21-30 years. (15)

Nishupriya et. al, reported $74.22 \%$ deaths in $21-30$ years. ${ }^{(16)}$

Yadav K et. al, reported 72.68\% deaths among 2029 years. $^{(17)}$

Purialka et. al. showed $71.53 \%$ of deaths occurred in 21-30 years age group. ${ }^{(18)}$

In this study, $52.2 \%$ deaths occurred in the post natal period followed by $47.2 \%$ deaths in the antenatal period.

Similar results have been obtained in other studies; Purandare et al, showed $73.33 \%$ deaths occurred in postpartum period and $26.66 \%$ in antenatal period; (13)

Saini and Gupta, et.al. reported $66.1 \%$ of post natal deaths; (15)

Nishupriya et. al,showed $62.8 \%$ postpartum deaths. (16) (17)

Yadav K et. al, reported $72.16 \%$ post natal deaths;

Purialka et. al, showed $63.08 \%$ of deaths in postnatal period. (18)

In the present study, 34\% deaths occurred within 0-6 hours of admission, 70.4\% deaths occurred within $24 \mathrm{hrs}$ of admission, $20.8 \%$ deaths within 48-78 hrsof admission.

Our observations correlate with other studies, $\mathrm{K}$. V. S. M. Sandhya Devi et al. reported 29.9\% deaths occurred within $<12$ hours of admission, $48.45 \%$ deaths occurred within $24 \mathrm{hrs}$ of admission, $27.83 \%$ deaths within 1-3 days, (9)

Saini and Gupta,et al.Reported 42.85\% deaths within 24 hours of admission and 57.15\% after 24 hours; (15)

Nishupriya et. al, showed that $54.63 \%$ of deaths were within 24 hours of admission, $19.58 \%$ within 25 48 hours $10.30 \%$ within $49-72$ hours and $15.46 \%$ after 72 hours of admission; (16)
Purialka et. al, reported $45 \%$ of deaths within 24 hours of admission. (18)

In the present study leading causes being hypertensive disorders 34\% (Pre-eclampsia \& Eclampsia), Severe Anaemia (20\%), Hepatic encephalopathy (13\%), Septic abortion (11\%), \& PPH (9\%).

Our observations correlate with other studies, Dr Sandhya Gupta et al reported the most common cause of maternal death in their study was hypertensive disorders of pregnancy, which is more common in primi patients (8)

K. V. S. M. Sandhya Devi et al. reported leading causes being haemorrhage $27.4 \%$, hypertensive disorders $23.71 \%$ (Eclampsia and severe preeclampsia) (9)

Purandare et. al,observed $70.83 \%$ deaths due to haemorrhage, $13.3 \%$ due to hypertension and $3.3 \%$ deaths due to sepsis. (13)

Vidyadhar et. al,reported $21.05 \%$ deaths due to haemorrhage, $10.52 \%$ deaths due to eclampsia and pulmonary embolism and $7.89 \%$ due to sepsis, $13.15 \%$ deaths due to heart disease and anaemia as cause in only $2.63 \%$ of deaths. (14)

In Saini and Gupta et. al. study, 60.5\% were direct deaths among which $23.9 \%$ were due to haemorrhage 21 . $1 \%$ due to sepsis and $7 \%$ due to eclampsia and $39.43 \%$ were indirect causes of death; (15)

Nishupriya et. al, showed postpartum haemorrhage $35.05 \%$ as the leading cause followed by hypertensive disorders $27.83 \%$ and anaemia $25.7 \%$; (16)

Yadav $\mathrm{k}$ et. al, reported $73.19 \%$ as direct obstetric deaths of which haemorrhage $43.16 \%$, hypertension $33.09 \%$, sepsis $12.67 \%, \quad 26.8 \%$ were indirect cause with anaemia as leading cause; (17)

Purialka, et.al. Reported sepsis $43.05 \%$ as leading cause followed by haemorrhage and eclampsia $22.22 \%$ and $31.94 \%$ respectively. (18)

Study Limitations: As with retrospective studies, any missing data from patient files affects the reliability of the data, but this was minimized by reviewing admission and death registers and all files from the records department. Additionally, the recorded causes of death were based on a clinical assessment of the attending medical doctors. 


\section{Conclusions}

Based on the results we found that hypertensive disorder (Pre-eclampsia \& Eclampsia) is an important cause of maternal mortality followed by Severe anaemia, Hepatic encephalopathy, Septic abortion and Postpartum haemorrhage.

Many developing nations lack adequate health care, family planning and pregnant women have minimal access to skilled labour and emergency care interventions such as antibiotics, oxytocics, anticonvulsant, manual removal of placenta and instrumental vaginal delivery are vital to improve the chance of survival.

Maternal mortality is a reflection of the standards of obstetric service and quality of healthcare. The audit of such mortality would help in identifying the problems and prevent recurrence by taking appropriate measures. Hence the present study was conducted at tertiary care hospital to review the maternal deaths and causes of maternal mortality.

Maternal health and newborn health are closely linked. It is particularly important that all births are attended by skilled health professionals, as timely management and treatment can make the difference between life and death for the mother as well as for the baby.

To improve maternal health, barriers that limit access to quality maternal health services must be identified and addressed at both health system and society levels.

\section{Ethical Clearance: Yes}

Financial Interest: None

Conflict of Interest: None

\section{References}

1. Trends in maternal mortality: 2000 to 2017 : estimates by WHO, UNICEF, UNFPA, World Bank Group and the United Nations Population Division. Geneva: World Health Organization; 2019.

2. "Health statistics and information systems: Maternal mortality ratio (per 100000 live births)". World Health Organization. Retrieved June 17, 2016.

3. Khan KS, Wojdyla D, Say L, et.al. (April 2006)."WHO analysis of causes of maternal death: a systematic review" Lancet. 367 (9516): 10661074. doi:10.1016/S0140-6736(06)68397-9.
4. Pregnancy Mortality Surveillance System - Pregnancy - Reproductive Health". CDC.

5.Maternal Mortality Ratio vs Maternal Mortality Rate on Population Research Institute website

6."Maternal health". United Nations Population Fund. Retrieved 2017-01-29.

7. Special Bulletin on Maternal Mortality in India 201517, Sample Registration System, Registrar General, India (November 2019).

8. Dr Sandhya Gupta et al Determinants of maternal mortality: A prospective study from single centre of Bhopal JMSCR Volume 07 Issue 05 May 2019 Page 799-803

9. K. V. S. M. Sandhya Devi et al. Study of maternal mortality in a tertiary care hospital.J of Evolution of Med and Dent Sci/eISSN- 2278-4802, pISSN2278-4748/Vol. 4/Issue 38/May 11, 2015 Page 6624-6630.

10. Adu-Bonsaffoh K, Oppong SA, Binlinla G, et al. Maternal deaths attributable to hypertensive disorders in a tertiary hospital in Ghana. Int $\mathbf{J}$ Gynaecol Obstet. 2013 Nov;123(2):110-3. doi: 10.1016/j.ijgo.2013.05.017.

11. Khan B, Deeba F, Khattak SN. Maternal mortality: a ten year review in a tertiary care setup. J Ayub Med Coll Abbottabad. 2012 Jul-Dec;24(3-4):124-7.

12. Yego F, Stewart Williams J, Byles J, et al. A retrospective analysis of maternal and neonatal mortality at a teaching and referral hospital in Kenya. Reprod Health. 2013 Feb;19(10):13. doi: 10.1186/1742-4755-10-13.

13.Purandare N, Singh A, Upadhya S, Sanjanwala SM, Saraogi RM. maternal mortality at a referral centre: a five year study. J obstetric gynaecology India. 2007; 57(3): 248-50.

14. Vidyadhar B. Bangal, Purushottam A. Giri, Ruchika Garg, maternal mortality at a Tertiary care teaching hospital of rural India: A retrospective study. Int J Bio Med Res. 2011; 2(4): 1043-1046.

15. Saini V. and Gupta M. Review of maternal mortality in an urban tertiary care hospital of North India: International Journal of Basic and Applied Medical Sciences, Vol. 4(1) January - April 2013, pp. 5964.

16. N Priya, V Ashok, V Suresh. Maternal mortality: ten years retrospective study. JK Science. Vol. 12 No. 3, July-September 2010: 134-136. 
17. Yadav K, Namdeo A, Bhargava M: A retrospective and prospective study of maternal mortality in a rural tertiary care hospital of Central India. Indian Journal of Community Health, Vol. 25, No. 1, JanMar 2013: 16-21.
18. P Alka, Y Indra, J Nisha. Maternal mortality in an urban tertiary care hospital of North India. The Journal of Obstetrics and Gynaecology of India May/June 2011: 280-285. 